\title{
Commentary
}

\section{Challenges faced by Community Palliative Care Services During the COVID-19 Pandemic-Experiences from a Hospice}

Eng Koon Ong, ${ }^{1,2}{ }_{M B B S}$, MMed (FM), FAMS, Gwendoline TL $\underline{\text { Soh, }}{ }^{1,2}{ }_{F R A C P,}$ FAChPM, Tan Ying Peh, ${ }^{1,2}$ MBBS, MMed (FM), FAMS, Tong Jen $\underline{\mathrm{LO}},{ }^{1,2}{ }_{M B B S, M R C P, M P H}$, Alethea CP $\underline{\text { Yee }},{ }^{1,2}$ MBBS, MRCP, FAMS

\section{Introduction}

The World Health Organisation declared the coronavirus disease 2019 (COVID-19) outbreak a pandemic on 11 March 2020, after more than 100,000 patients in 114 countries were infected. Singapore reported its first case of imported COVID-19 infection on 23 January $2020 .{ }^{1}$ As the outbreak escalated globally, strict measures were progressively implemented by the Singaporean government that included entry restrictions and social distancing. By early April 2020, local transmissions had increased exponentially, and the government introduced further measures like cessation of non-essential services, closure of public spaces and schools, and work from home orders. This has led to unprecedented challenges in how we provide healthcare, especially in the area of palliative care.

Palliative care aims to provide patients with life-limiting illnesses good symptom control and relief from psychological distress for themselves and their families. ${ }^{2,3}$ Patients under the care of community hospice services report higher levels of satisfaction in symptom control, support to caregivers, and achievement of home deaths compared to hospital patients. ${ }^{4,5}$ Here we report the challenges faced by a hospice in Singapore in the delivery of palliative care during the COVID-19 pandemic, and how the experience of death and dying has been impacted by the crisis.

Assisi Hospice is a charity organisation that provides the whole continuum of inpatient ( 85 beds), day care and home care services. In line with national COVID-19 measures, the hospice came up with guidelines to reflect these measures on the ground (Table). The experience of Assisi Hospice in delivering palliative care in a pandemic mirrors that of similar hospice providers in Singapore. We have chosen to describe the challenges based on each setting below and the strategies implemented to mitigate them.

\section{Challenges in Home Hospice Service}

\section{Barriers to a Home Death}

The main strategy employed to curb disease transmission in COVID-19 is based on early identification and rapid isolation of confirmed cases. The government recommends that all medically unstable patients with suspected pneumonia be referred to hospitals for evaluation and treatment. However, pneumonia is often the terminal event in patients with life-limiting illnesses. Without COVID-19 testing, it can be difficult for the home hospice team to decide clinically if the pneumonia is secondary to COVID-19, or part of dying from underlying illness. Referring these patients to the hospitals not only places undue pressure upon the acute sector, but also deprives patients of their wish to be cared for and to pass away at home. Yet, nursing a dying patient at home without realising that he/she is a COVID-19 positive case has public health implications. To manage this conundrum, for actively dying patients at home with signs of pneumonia (but no apparent risk factors for COVID-19), and whose preferred place of death is at home, our home hospice team will visit with full personal protective equipment (PPE) to support care at the end of life.

The pandemic also posed challenges to caregiving at home. Employment of foreign domestic helpers became limited and most families cannot afford private caregivers. Some family members are able to care for patients while working from home, but this will stop once they return to work. Admission to our inpatient service is an option for those with a short prognosis of usually less than 3 months with no carers. Alternatively, they can tap into short-term, government funded caregivers with the help of our social workers.

\footnotetext{
${ }^{1}$ Assisi Hospice, Singapore

${ }^{2}$ Division of Supportive and Palliative Care, National Cancer Centre Singapore, Singapore

Address for Correspondence: Dr Ong Eng Koon, Division of Supportive and Palliative Care, National Cancer Centre Singapore, 11 Hospital Drive, Singapore 169610.

Email: ong.eng.koon@singhealth.com.sg
} 
Table. National Measures and Corresponding Protocols in Assisi Hospice

\begin{tabular}{|c|c|c|c|}
\hline \multirow{2}{*}{$\begin{array}{l}\text { National Measures } \\
\text { to Contain the } \\
\text { COVID-19 Pandemic }\end{array}$} & \multicolumn{3}{|c|}{ Protocols Instituted to Overcome Challenges } \\
\hline & Home Hospice & Inpatient Hospice & Day Hospice \\
\hline \multirow[t]{3}{*}{$\begin{array}{l}\text { Patients with high probability } \\
\text { of COVID-19 infection are } \\
\text { to be referred for assessment } \\
\text { in the hospital }\end{array}$} & $\begin{array}{l}\text { Phone calls are made prior } \\
\text { to home visit to assess for } \\
\text { symptoms of pneumonia } \\
\text { and risk factors for } \\
\text { COVID-19 infection }\end{array}$ & $\begin{array}{l}\text { Patients with no ARI symptoms } \\
\text { admitted from home are swabbed } \\
\text { for COVID-19 and sent to ED if } \\
\text { positive. All admissions from RH/ } \\
\text { CH are swabbed and proven } \\
\text { negative prior to admission }\end{array}$ & $\begin{array}{l}\text { Phone calls are made prior to } \\
\text { attendance at the day care to } \\
\text { assess for risk factors of } \\
\text { COVID-19 infection }\end{array}$ \\
\hline & $\begin{array}{l}\text { Patients with ARI symptoms } \\
\text { OR risk factors for COVID-19 } \\
\text { are asked to visit the ED for } \\
\text { further evaluation assessment }\end{array}$ & $\begin{array}{l}\text { Patients who develop new onset ARI } \\
\text { symptoms during admission, for } \\
\text { which no underlying cause } \\
\text { can be attributed, will be } \\
\text { swabbed for COVID-19 }\end{array}$ & $\begin{array}{l}\text { Patients with ARI symptoms } \\
\text { are denied entry and asked to } \\
\text { visit the ED for further evaluation }\end{array}$ \\
\hline & \multicolumn{3}{|l|}{$\begin{array}{l}\text { Patients with a prognosis of days } \\
\text { and with home as preferred place } \\
\text { of death will be visited by the } \\
\text { home hospice team in full PPE }\end{array}$} \\
\hline \multirow[t]{3}{*}{ Safe distancing measures } & $\begin{array}{l}\text { Home visits are kept to a maximum } \\
\text { of } 30 \text { minutes as far as possible. } \\
\text { Stable patients are supported over } \\
\text { phone or video calls. Visits are } \\
\text { reserved for unstable or dying } \\
\text { patients (unstable defined as } \\
\text { those needing urgent or } \\
\text { on-site assessment and } \\
\text { symptom management) }\end{array}$ & $\begin{array}{l}\text { During circuit breaker period, } \\
\text { only } 4 \text { designated visitors are } \\
\text { allowed entry into the wards with a } \\
\text { maximum of } 2 \text { for stable patients } \\
\text { and } 4 \text { at any one time if the patient } \\
\text { is actively dying. After circuit } \\
\text { breaker, this has been relaxed to } \\
\text { any } 4 \text { visitors at any one time }\end{array}$ & $\begin{array}{l}\text { Day care is limited to patients with } \\
\text { inadequate family support and } \\
\text { pressing care needs }\end{array}$ \\
\hline & $\begin{array}{l}\text { During home visits, family } \\
\text { members must be masked } \\
\text { and practise safe distancing } \\
\text { from staff }\end{array}$ & $\begin{array}{l}\text { These restrictions may be } \\
\text { further tightened if the } \\
\text { community spread escalates }\end{array}$ & $\begin{array}{l}\text { No group activities during circuit } \\
\text { breaker. After circuit breaker, group } \\
\text { activities are limited to a maximum } \\
\text { of } 5 \text { persons a group }\end{array}$ \\
\hline & \multicolumn{3}{|c|}{$\begin{array}{l}\text { 1. Staff are segregated into teams, all meetings are conducted online. } \\
\text { 2. No social gatherings are allowed. } \\
\text { 3. Daily temperature-taking and SafeEntry* app check in twice a day by staff. } \\
\text { 4. Staff must wear surgical masks and practise strict hand hygiene at all times during work. Full PPE is donned when } \\
\text { with patients with suspected pneumonia/awaiting swab results, or when performing aerosol procedures. }\end{array}$} \\
\hline
\end{tabular}

ARI: Acute respiratory illness; CH: Community hospital; ED: Emergency department; PPE: Protective personal equipment; RH: Restructured hospital *Government of Singapore. SafeEntry-Because every scan counts towards our fight against COVID-19. Available at: https://support.safeentry.gov.sg/hc/ en-us/articles/900000667463-What-is-SafeEntry-. Accessed on 20 August 2020. 
Our 24-hour service continues to provide support for end-of-life care at home. With such measures, there was an upward trend for hospice and home deaths from January to May 2020, while hospital deaths were slightly decreased after circuit breaker started in April (Fig. 1).

\section{Impact on Continuity of Care}

For home care patients with risk factors for COVID-19 but are stable, the home hospice team will discontinue home visits to reduce risk of transmission. Support is provided via phone or videoconferencing for 14 days after the exposure history before a home visit is allowed. This lack of direct clinical assessment can impact accurate identification of problems, resulting in inadequate symptom control and management of emotional distress. As a result, some patients are compelled to seek care in hospitals if they are unable to cope at home, thereby adding to the burden of hospitals as well as affecting the continuity of care in the community.

Conversely, patients and family members may prefer to remain at home as they perceive the risks being infected with COVID-19 to be higher in the hospitals. Equally hospitals try to limit nonCOVID-19 related hospital admissions and outpatient appointments. As such, patients who can benefit from hospital-based treatments may end up with poorer health outcomes.

Telehealth in pre-COVID-19 times is the norm for home hospice care but this is usually in the form of phone consultations to complement home visits. During the pandemic, there is a trend of increased phone calls for assessment and advice, with a corresponding trend of decreased home visits from January to May 2020 (Fig. 2 and 3). Occasionally, families will send videos of patients to provide hospice staff with a better visual understanding of the patient's condition. We are looking into videoconferencing platforms as another means of teleconsultation because we anticipate an increased usage of telehealth in a pandemic.

\section{Impact on Bereavement}

With national safe-distancing measures in place, attendance at funerals are also subject to evolving COVID-19 measures. Initially, only immediate family members were permitted to attend the funeral of

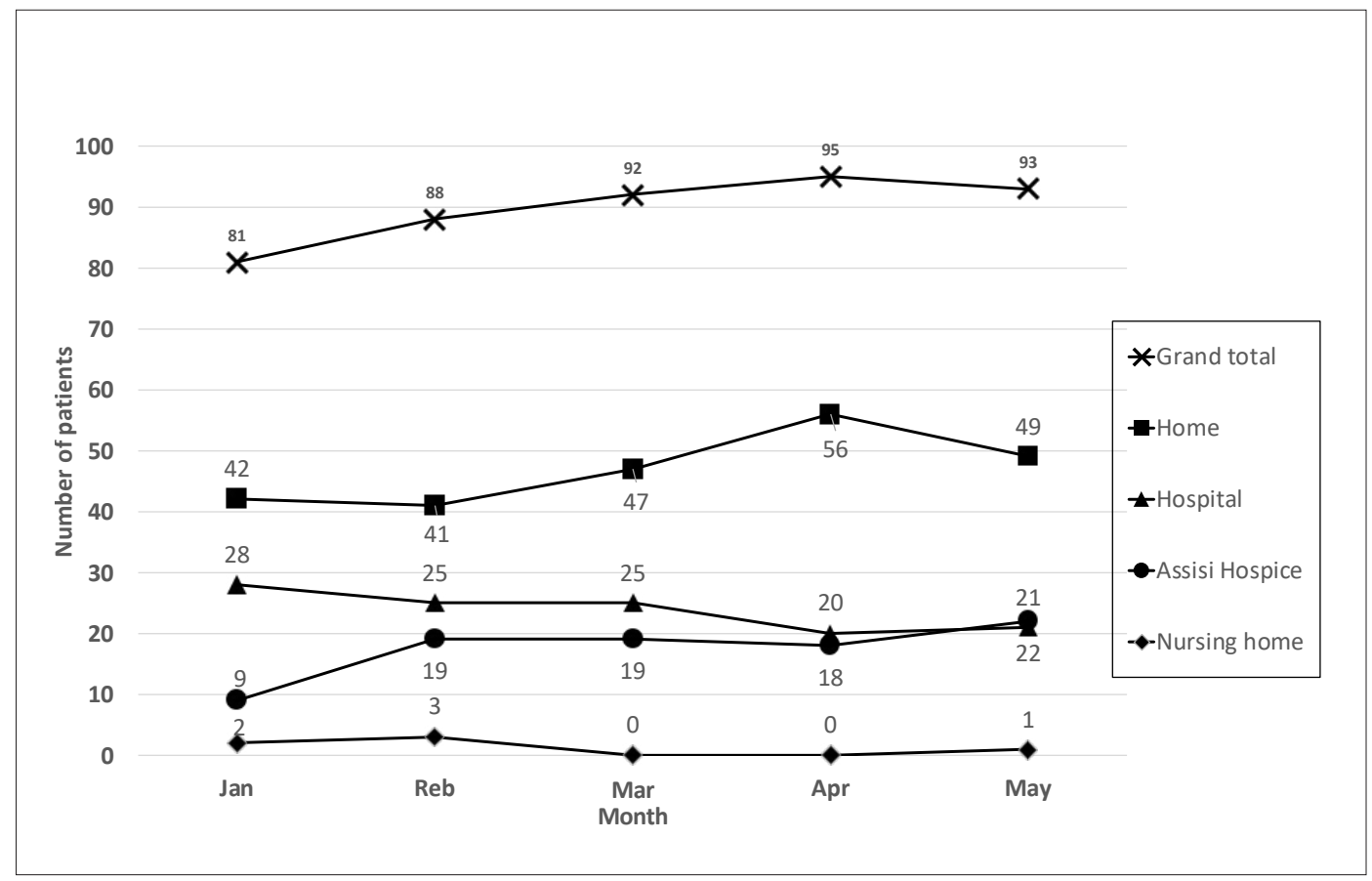

Figure 1. Place of death of patients 


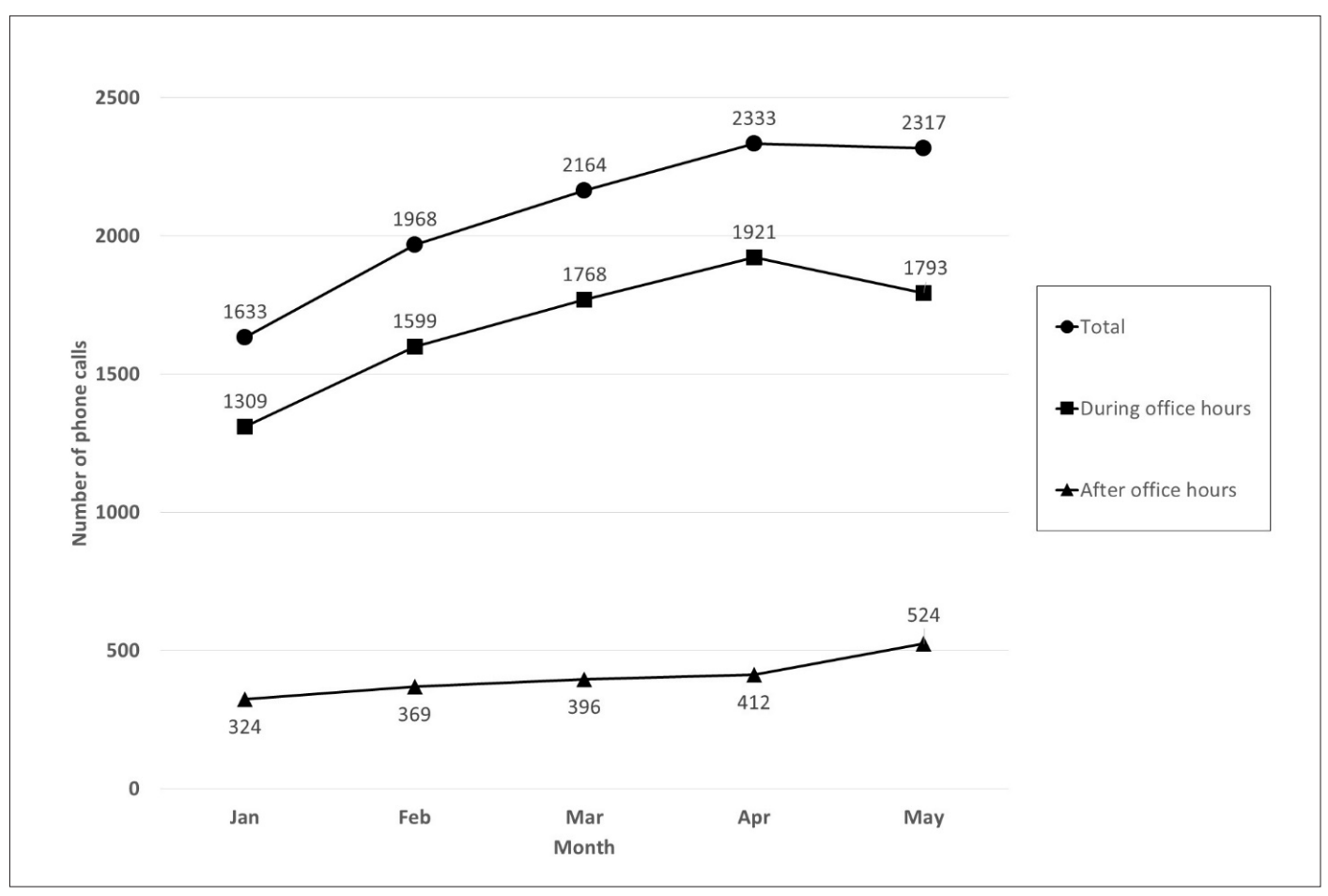

Figure 2. Number of phone calls made by hospice staff

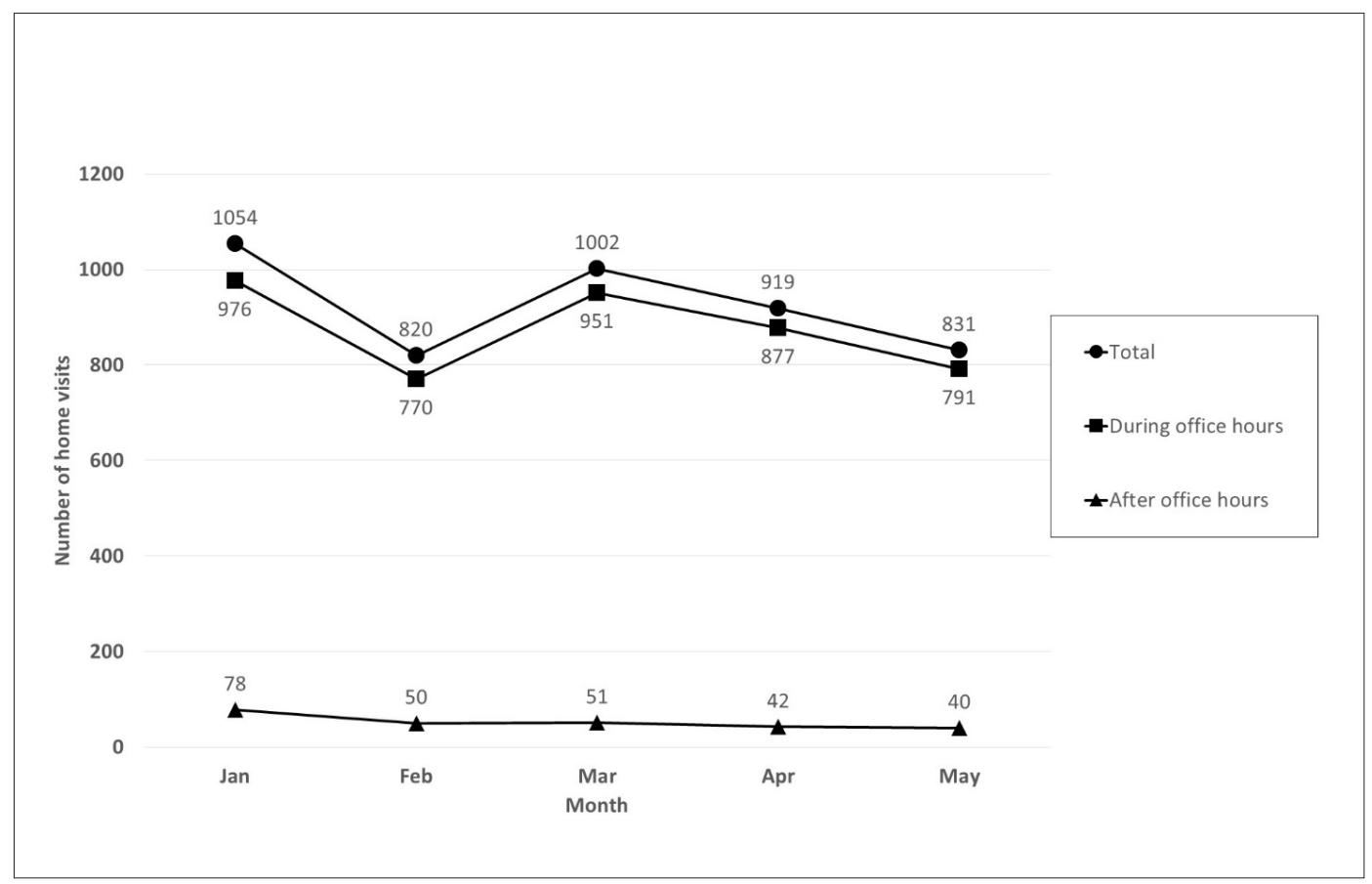

Figure 3. Number of home visits made by home hospice staff 
their loved ones. Although measures have since been relaxed, the bereaved will continue to be limited by space, time and support to grieve before the pandemic is controlled. Similarly, home hospice staff who would normally attend funerals of patients they know well are constrained by national guidelines and will need to find other means of closure.

\section{Challenges in the Inpatient Hospice Service}

\section{Increasing Capacity}

During the COVID-19 pandemic, hospitals are under tremendous strain to cope with the increasing numbers of infected patients. Assisi Hospice witnessed a $15 \%$ increase of bed occupancy rate. The increased patient load and stay-at-home orders imposed on some staff with risk factors inevitably posed significant manpower challenges.

\section{Restrictions in Activities, Movements and Visitation}

The inpatient hospice provides a compassionate and conducive environment for patients and their loved ones to spend meaningful and quality time together in the last leg of their journey. Before the pandemic, there were no restrictions on visiting hours and visitor numbers. Patients were allowed time for excursions or "home leave" from the hospice. Group activities like art and music therapy were conducted regularly. Since COVID-19, in line with national safe distancing measures, Assisi Hospice has had to impose significant restrictions, including visitor numbers, outings, home leave and group activities. These have resulted in distress for many families who were unable to spend time with their loved ones in their last days. Staff had to manage angry and distressed families while patients were denied certain activities they used to enjoy.

To support our patients and families, the use of phone and video calls have been encouraged. These have been well received and are facilitated by staff, especially for patients who may need technical advice. In addition, our therapists continued to engage patients individually even as group sessions have stopped.

\section{Challenges to Hospice Day Care Service}

Hospice day care provides patients living with life-limiting illnesses the opportunity to engage in social activities in a safe environment. Such social interactions are valuable in helping patients maintain relationships and a sense of normalcy.
In the early days of the pandemic, patients were screened daily for COVID-19 risk factors prior to attendance. Group activities were reduced and eventually suspended. When stricter national measures were implemented, Assisi Hospice day care was only permitted to admit patients with inadequate family support and pressing care needs. The majority of day care patients were kept away at home, losing precious opportunity for social engagement. Carers could no longer enjoy the respite offered by day care and had to juggle between work and caregiving.

To address the above challenges, the day care team developed videos comprising of exercise regimens, therapy instructions, as well as art and music sessions according to our patients' needs. Patients were also sent individualised care packs which included exercise sheets, materials for art and craft, gardening tools, and even soil and plants.

\section{Psychological Distress of Hospice Staff}

The impact of COVID-19 measures affects staff in all 3 services of the hospice. In home hospice, staff may be conflicted by the inability to honour the patients' preference to be cared for at home in view of national measures to minimise community transmission. Unlike hospitals, home hospice services tend to have lower manpower capacity to buffer measures like staff segregation. Together with a sense of isolation from team segregation, these issues can lead to anxiety, hopelessness and physical exhaustion, increasing the risk of burnout.

Apart from team segregation, staff from all 3 services were affected by other measures such as mandatory mask-wearing, travel and leave restrictions, transport and even accommodation arrangements.

Foreign staff residing in Singapore were unable to travel home to visit their families. Foreign staff commuting daily from their accommodation in neighbouring Malaysia to the hospice were no longer able to do so. In line with the Ministry of Health, Singapore, advisories, foreign staff were provided on-site accommodation or housed in hotels.

With widespread community transmission, the fear of being infected despite protective equipment remains a real concern to all staff. As such, a sufficient supply of PPE was ensured by timely replenishment of stock and prudent use based on latest evidence. All staff underwent competency training and assessment on PPE use to ensure their safety. 
There were regular sessions between the staff and management for open communication and timely problem solving. To boost morale, regular sessions of live singing by the music therapists over the public address system took place twice a week. Live concerts over YouTube were also held with song dedications made as a show of encouragement and gratitude.

\section{Conclusion}

The COVID-19 pandemic has impacted how we practice healthcare in the various disciplines of medicine globally. In particular, community palliative care services including inpatient, home and day hospices face significant challenges in view of strict national measures, to deliver care aligned to patients' goals and values, especially when patients are faced with death and dying. Public health interests supersede individual preferences for end-of-life care. Hospice staff need to adapt quickly to the rapidly evolving situation and constant stream of new government regulations, while experiencing anxiety over risk of infection to self and others, and concern over quality of patient care in a climate of uncertainty. Nevertheless, palliative care services can respond with a growth mindset of resilience, innovation, and adaptability to continue to deliver quality care in a pandemic.

\section{REFERENCES}

1. Wong JEL, Leo YS, Tan CC. COVID-19 in Singapore-Current experience: critical global issues that require attention and action. JAMA 2020;323:1243-44.

2. World Health Organisation. WHO definition of palliative care. Available at: https://www.who.int/cancer/palliative/definition/en/. Accessed on 24 April 2020.

3. Goh CR, Sethi VK. Palliative care in Singapore-good medicine given with compassion. Ann Acad Med Singapore 1994;23:127-8.

4. Finlay IG, Higginson IJ, Goodwin DM, Cook AM, Edwards AG, et al. Palliative care in hospital, hospice, at home: results from a systematic review. Ann Oncol 2002; 13:257-64.

5. Finkelstein E, Malhotra C, Yee AC. Improving the end-of-life wexperience in Singapore: building capacity in palliative care education and research. Ann Acad Med Singapore 2014;43:1-2. 